\title{
Evolutionary geography and the Afrotropical model of hominin evolution
}

\author{
Robert A. Foley \\ Leverhulme Centre for Human Evolutionary Studies \\ Department of Archaeology and Anthropology \\ University of Cambridge
}

Fitzwilliam Street

Cambridge $\mathrm{CB} 2 \mathrm{IQH}$

UK

\begin{abstract}
During the second half of the twentieth century, the evidence that Africa was central to hominin evolution became overwhelming. The earliest occurrences of most of the fossil hominin taxa and lithic technologies are to be found in Africa, and there is strong evidence that humans are closely related to African apes, and that the genetic origins of modern humans lie in Africa. The aim of this paper is to consider the possible evolutionary and ecological basis for this - why should Africa be so central? After considering biases in the record that might promote an African record, the paper uses evolutionary geography - the spatial and distributional properties of the evolutionary process to consider the factors that lead to higher rates of speciation, novelty and dispersals, as well as the way in which the African ecological context is structured and changes through time. Critical factors identified are the variable role of the Sahara, the different extent of the Afrotropical realm as climate changes, the impact of basin structure, and the effect of variable topography and surface water distribution. The key factor is biogeographic regionalisation and the share evolutionary histories that this reflects. It is proposed that hominin evolution is globally part of the Afrotropical realm and its history, and that biogeographical variation within Africa is key to understanding the diverse nature of African hominins and their potential to disperse beyond the continent. More broadly, the paper shows the importance of placing hominin evolution into a comparative and theoretical framework, particularly evolutionary geography, and proposes a more general basis for the Afrotropical Model of Hominin Evolution.
\end{abstract}

\section{Introduction: the Afrotropical Model of hominin evolution}

When Raymond Dart described the first fossil hominin in 1924 at Taung [I], few would have predicted that by the end of the century Africa would have moved from a peripheral to a central role in human evolution. Both theory and data seemed to point to Eurasia as a more probable place of 
origins [2]. Ironically, Darwin's prediction that Africa would be the place of human origins had largely been forgotten.

Now, no-one would challenge the substantial role of Africa - especially sub-Saharan Africa in the evolution of the hominin lineage. A simple measure is to look at first appearances (Table I). The earliest hominins, the earliest (and only) australopithecines, the earliest genus Homo, the earliest hominin with significantly larger brain size and human body proportions, the earliest anatomically modern humans. Against that, Eurasia can claim one definite palaeontological first appearance - $H$. neanderthalensis - plus the genetic ghost lineage, the Denisovans. Homo georgicus, H.antecessor, $H$. floresiensis. H. erectus and H. heidelbergensis are hard to place, as it depends upon taxonomic definitions, but could have Eurasian origins. Of the 28 taxa so far identified in the hominin fossil record [3, 4], 24 occur in Africa, and 2I exclusively in Africa. All hominin genera have African origins.

\begin{tabular}{|l|l|l|}
\hline First appearances & Age $(\mathrm{ma})$ & Reference \\
\hline $\begin{array}{l}\text { Earliest modern human } \\
\text { behaviours }\end{array}$ & 0.16 - O.I ma & {$[62]$} \\
\hline Earliest Homo sapiens & $\sim 0.3-0.2 \mathrm{ma}$ & {$[\mathrm{I7}, 27,63]$} \\
\hline Earliest Mode 3 technologies & $\sim 0.3 \mathrm{Ma}$ & {$[64]$} \\
\hline Earliest Homo heidelbergensis & $\sim 0.7 \mathrm{Ma}$ & {$[65]$} \\
\hline Earliest Acheulean & I.7 Ma & {$[66]$} \\
\hline Earliest Homo ergaster/erectus & I.9 Ma & {$[67]$} \\
\hline Earliest Oldowan technologies & $2.5 \mathrm{Ma}$ & {$[68]$} \\
\hline Earliest Homo & $2.8-2.3 \mathrm{Ma}$ & {$[69]$} \\
\hline Earliest technology & $3.3 \mathrm{ma}$ & {$[70]$} \\
\hline $\begin{array}{l}\text { Origins and radiation of } \\
\text { australopithecines }\end{array}$ & $4.2-2 \mathrm{Ma}$ & {$[7 \mathrm{I}]$} \\
\hline Earliest hominins & $\sim 7-5 \mathrm{Ma}$ & {$[22]$} \\
\hline
\end{tabular}

Table 1 Occurrence of first appearances in Africa during the course of hominin evolution

A similar story can be found among the lithic traditions (Table I) - the first stone tool technology (Lomekwian), the first Oldowan, the earliest Mode 2 technologies, and the earliest Mode 3. Looking more broadly at the archaeological record, fire, use of ochre, and microliths are all found earlier in Africa than elsewhere, and there is widespread acceptance of the evidence for what might broadly be called modern human behaviour in Africa by around Ioo,ooo years ago.

It is not just the palaeontological and archaeological records that underpin the Afrotropical Model of human evolution. Comparative genetics have shown that the sister clade of the hominins is the chimpanzee/bonobo one [5], and that in turn is part of an African ape clade, suggesting, in line with Darwin's proposal [6], that hominin origin is an African event. 
Currently genetics cannot inform on australopithecine diversity, or the early evolution of Homo, but both ancient and contemporary DNA has also shown a) that the ancestral population of modern humans was in Africa [7]; b) that Africans have much larger genetic diversity than all Eurasia [8]; c) that Eurasian populations are descended from African ones [9, IO]; and that African ancestral populations did not interbreed with Neanderthals and Denisovans [II]. This has been clear for some time from the uniparental markers, mtDNA and Y-chromosome, and now firmly confirmed by whole genomes and multiple autosomal markers.

Even when the focus moves beyond Africa, the framework remains African. Eurasian evolution and prehistory is defined in terms of 'out of Africa' models - Out of Africa I (H. ergaster) erectus) [12], Out of Africa 2 (modern humans) [13], and more extensively, 'out of Africa again and again' (multiple dispersals) [14].

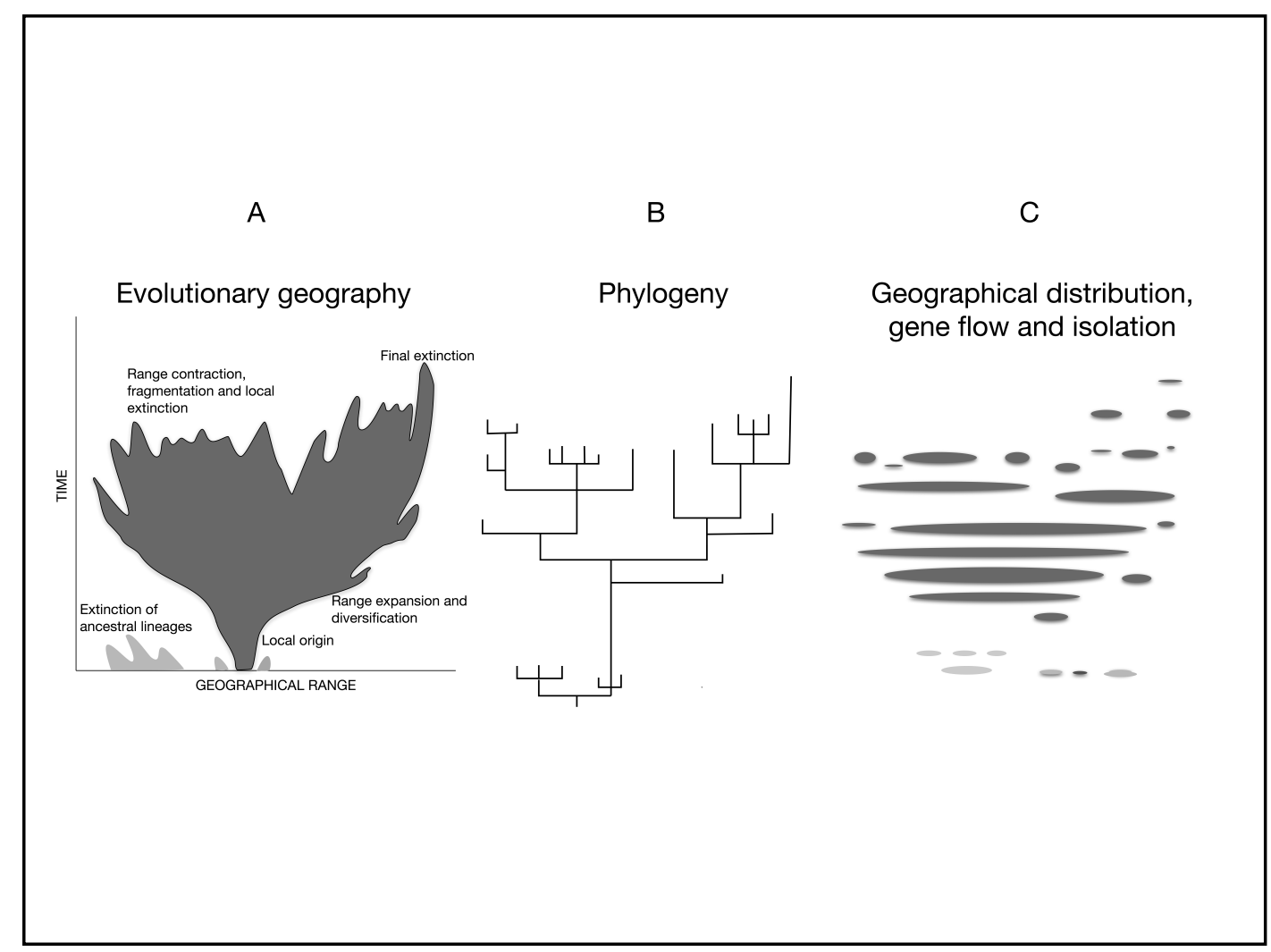

Figure 1. Evolutionary geography focuses on the the way in which change occurs first as a result of spatial distribution (A), resulting in demographic anad adaptive divergence through lineages (B), with variable levels of gene flow or discontinuities, and as such evolutionary change through time (C). See [20] and [21] for further details.

There is, on current evidence, little chance of this Afrocentric model being overturned, although there may be challenges to some elements of it - for example, that the African apes were in fact 'recent' Eurasian immigrants [5], or that H. erectus (defined broadly) evolved in Asia and subsequently dispersed into Africa [I6], or that northern rather than sub-Saharan Africa may have played an important role in modern human origins [I7][I8]. Neither is there much to be gained by thinking of this pattern in terms of 'importance'; it is not that Africa is more important than other regions, but that the ecological and demographic conditions in different regions prompt different evolutionary processes. Higher latitudes, for example, are subject to more magnified habitat change, and so responses are likely to be different (often extinction), compared to tropical regions. Cold 
climates demand particular adaptive responses which may be less likely to lead to novelty. This is certainly the pattern across broader biological systems, leading to such patterns as the declining levels of diversity with latitude [I9].

A more profitable approach is to ask how and why Africa seems to have been, for hominins, such a promotor of change and diversity. The framework adopted here is broadly speaking referred to as evolutionary geography. Evolutionary geography investigates the role of spatial factors in the evolutionary process [20]. It differs from biogeography in that it operates at a variety of scales. While phylogenetic patterns are an important element, its primary focus is the investigation of the environmental (biotic and abiotic) and demographic conditions for both range expansions and contractions in the history of a lineage, and the way this plays out from the micro to the macroevolution levels [20]. Geographical approaches to evolution are significant because spatial distributions and their context underlie most processes. "Evolutionary change occurs first as a result of spatial distribution - population dispersals and contractions, fragmentation and isolation in response to vicariance, shifting habitat boundaries, and so on. Changes in distribution result in altered selective pressures, different demographic parameters, new levels of gene flow or discontinuities, and as such evolutionary change through time is the end product of geographical processes" [2I] (Figure I). This paper will examine the primacy of Africa in human evolution in the context of geographical patterns, and in particular that hominins share the evolutionary history and processes of the biogeographical area to which they belonged, and that is the basis for an Afrotropical Model of hominin evolution.

\section{Africa and the evolutionary process}

Before considering the particular role of Africa on hominin evolution, it is necessary to examine some broader issues that may influence both the visibility of African fossil history and the probability of an evolutionary event taking place. The former are issues of sampling and taphonomy, while the latter are largely about biogeography and evolutionary processes.

\section{Taphonomic bias}

One possibility that should entertained is that the Afrotropical Model is an artefact of preservation. The uneven nature of the fossil record is well-established - preservation of fossils is rare, exposure to discovery is more rare, and furthermore, it is highly patchy in relation to both species and time. Perhaps Africa is not just a good place for hominins to have lived, but simply a good place for them to have subsequently died in terms of becoming part of the fossil record. Africa may have particularly good conditions for fossilisation and discovery. Support for that view could be found in the patchy distribution of the record of hominin evolution. By and large, what is known comes from three major sources - the East African Rift System (EARS), the limestone caves of the Transvaal, and the rock shelters and caves of the Cape. This is not to say there are not other important regions Chad, for example is the source of the oldest potential hominin (Sahelanthropus tchadensis) [22], and the north African coastal caves, such as Haua Fteah and Jabel Irhoud 23,24- but that these regions are particularly rich, and probably account for well over $90 \%$ of all hominin fossils.

The reasons for this are largely geological. The EARS has created numerous fluvial and lacustrine systems that have subsequently been buried and re-exposed by rifting, ideal conditions for both fossilisation and research [23]. The Pliocene and Pleistocene caves in the Transvaal are one of the few karstic systems in Africa, and are highly fossiliferous [24]. The Cape has many caves which record 
the more recent elements of human evolution [25, 26]. Much of the rest of Africa is either covered with dense rainforest, has highly lateritic sediments that do not preserve fossils, or have been highly denuded by erosion. Hominins have been found in none of these.

We cannot exclude the case for taphonomic exceptionalism, but there are a number of points that can be made against it. The most important of these are based on genetics. This is entirely independent of taphonomic factors, yet both the close relationship between humans and African apes and the greater human diversity and inferred time depth among African populations would point strongly to Africa as being significant for both early hominins and modern human evolution. There is a good match between the estimates for the divergence of the last common ancestor of chimpanzees/bonobos and hominins and the fossil record, so the timing fits as well [5]. There is also a consistency for the dates of the last common ancestral population of modern humans and Neanderthals - in the region of $150-300 \mathrm{Ka}$ [18, 27-30], the earliest anatomically modern humans. Equally, the dates of both archaic hominins and modern humans in Eurasia are consistent with this pattern [3I-33]. The centrality of Africa in the human story may benefit from geological history, but at a comparative scale it is likely to be correct. What is uncertain is whether the regional, within-Africa pattern is not an artefact of that history.

\section{Size and chance}

When it is stated that humans - or hominins - evolved in Africa, it is not a particularly discriminating perspective. Africa is a very large continent. The Afrotropical Model narrows down the origins to approximately one quarter of the Old World, and once one has excluded the high latitudes where it is unlikely such origins would be found, probably to half the Old World. Africa is larger than Europe, China and the USA combined. A null model would be that given its size, it should be expected that a very large proportion of evolutionary events should occur there by chance. While this must be a possibility, it is clearly one that cannot be tested except by excluding other possibilities related to environmental hypotheses.

\section{Latitudinal gradients and the importance of the tropics}

One such is the latitude diversity gradient hypothesis. It has long been observed that there are many more species at the tropics, and that species diversity declines with increasing latitude. There are many explanations for this observation, but the pattern is remarkably robust across taxa, trophic level and habitat [19]. Whatever the ultimate causation - energetics, climatic stability, land area, etc. the implication of all is that rates of speciation are higher in the tropics than at high latitudes. The adaptive corollary of this is that there is a higher rate of evolutionary novelty. As Africa has the highest land mass of tropical and sub-tropical environments, the pattern seen for hominins could be said to reflect a much broader evolutionary process; hominins are simply following general evolutionary principles. Rolland et al [34] have shown that the latitudinal gradient is not just a reflection of ecological equilibrium now, but rates of speciation. There is a higher speciation rate in the tropics than in temperate zones, and this can be seen for mammals as a whole, and particular orders. In effect, mammalian species diversity reflects an 'out of the tropics' model, and such a model will necessarily show a strong signal in Africa. Hominin evolution reflects both the latitudinal gradient in terms of taxic diversity, and the high rate of endemism.

This pattern is not found solely for inter-specific diversity. Studies of cultural and linguistic diversity among humans have shown a similar latitudinal gradient, from tropics to high latitudes [35- 
37]. This suggests there are at least analogous processes occurring in the way in which boundaries are formed between human groups, with a higher probability of such boundaries in tropical latitudes. Nettle [35] has argued that this is a product of risk reduction in high latitudes; a complimentary hypothesis is that niche partitioning and isolation is possible at smaller scales in low latitudes [38]. This would suggest that the higher rate of speciation among hominins may reflect not just environmental factors, but integrates with evolving aspects of human cultural behaviour.

\section{Endemism: Africa as a species factory}

Endemism is the central concept in the Afrotropical Model - most hominin taxa are endemic to Africa, having originated there. This high level of endemism is an African characteristic; endemism levels at family rank (proportion of endemic families per biome) is highest in the Oceanic biome, followed by Neotropics. The Ethiopian biome is ranked next. However, what is perhaps most striking is that at family level there are no endemics in the Palaearctic. Eurasia, in terms of the origins of higher taxa, is a recipient, not a donor. The same pattern is seen at species level for zoogeographic regions [39].

In an analysis of global patterns of endemism, Kier et al. [40] showed that species endemism was generally higher in island zones, but among the mainland regions it was the tropics that had the highest levels of endemism, and within Africa, parts of East Africa had the highest levels among mammals. Fortelius et al. [4I] have introduced the idea of "species factories" - in particular, suggesting that the Turkana Basin is one such; specific conditions of isolation, resilience, and resource availability provided the ba lanced between survivorship (so species did not become extinct), but sufficient changes in conditions to prompt evolutionary novelty. If this is the case - particularly for tropical Africa - then the high level of African endemism among hominins would be part of a more general evolutionary pattern.

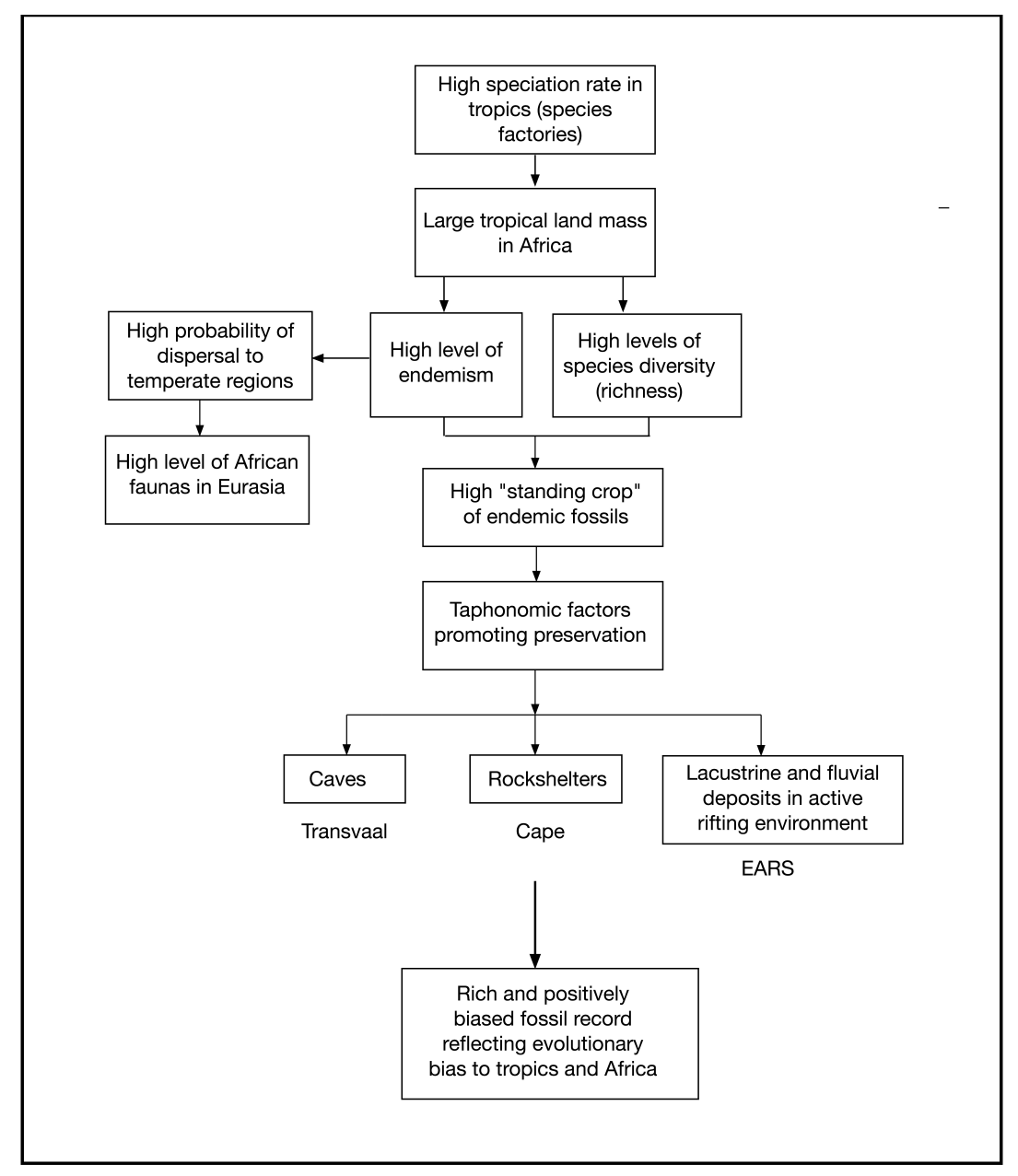

Figure 2. Factors influencing the biological and taphonomic processes resulting in a rich Afrotropical Model of hominin evolution. 


\section{Community and co-evolution}

A final factor is that no lineage evolves in isolation, but as part of a community and through co-evolutionary interactions. Such co-evolutionary processes can be intimate, intense and obligatory - for example, the co-evolution of acacia trees and ants. More general long term patterns have also been observed among predators and prey - for example, in changes in limb lengths across the Cenozoic [42]. At a broader level, there is a process of community evolution, where many lineages coevolve as a response to changing environmental conditions [43]. The expansion of the grasslands in the Late Miocene and Pliocene in East Africa created conditions suitable for many mid to large body sized mammals, and an increase in grazing [44], although the detailed sequence may have been complex [45]. The typical African savanna or Ethiopian fauna evolved concurrently in response to this, and hominins in Africa are likely to have been a part of that process, and should be considered a member of the African later Cenozoic biome. More speculatively is whether there were more intense competitive interactions between lineages so that this community evolution took on a Red Queen component $[43,46]$.

In summary, the evolutionary record of Africa is a product of many factors, some of which may inhibit our understanding (for example areas with no fossil preservation), while others may promote it. Equally, some intrinsic characteristics of the evolutionary process may have promoted great evolutionary change than was to be expected in other areas (Figure 2).

\section{The evolutionary geography of Africa}

Against this broad evolutionary background, we can examine the role of Africa in hominin evolution more specifically, and, in particular, how its geography has been significant in this. We can consider how Africa, as an evolutionary unit, is neither constant nor homogenous.

\section{The two Africas}

Africa is, geologically speaking, a single continent, and has been a unit in plate tectonics since the split from South America around Ioo Ma. Until the Early Miocene Africa was essentially an island continent, unconnected to Eurasia. From the Early Miocene a land bridge was established, and faunal exchanges occurred, including by hominoids. In that context, Africa is a continent with a deep evolutionary history

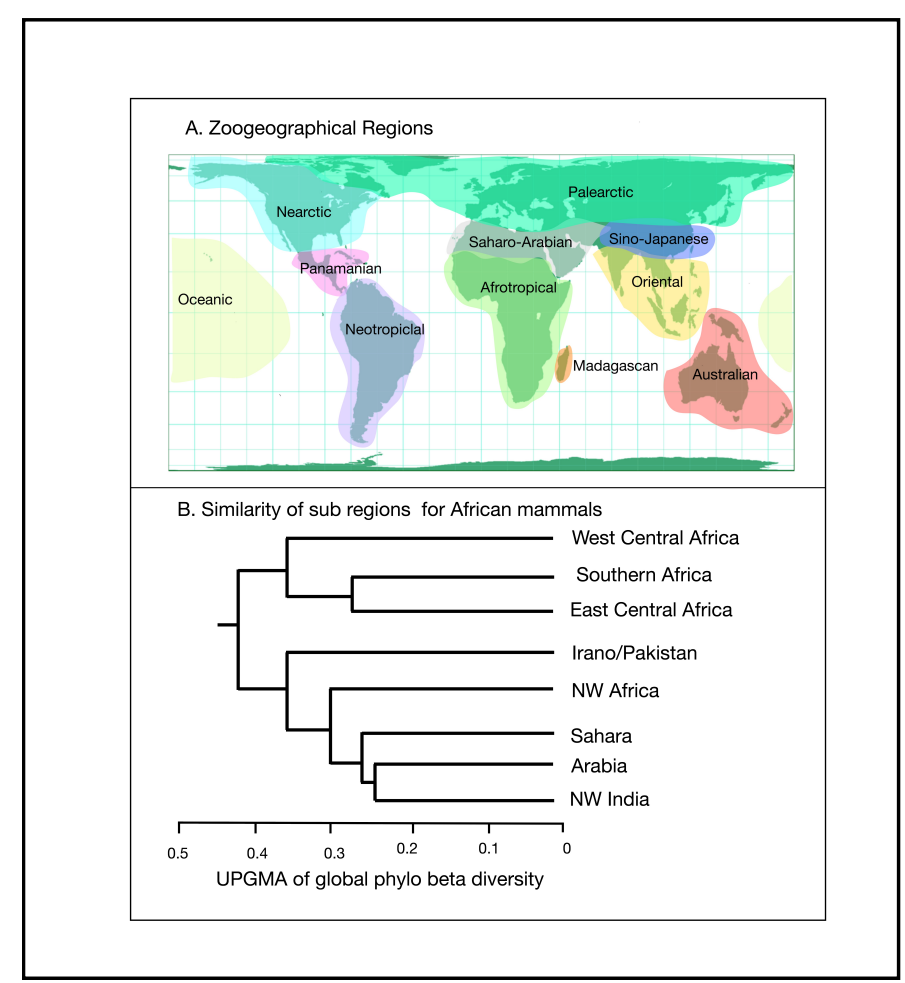

Figure 3. A. Zoogeographical zones of the world; and B. Similarities between African zoogeographical zones and adjacent Eurasian ones. Adapted from [39]. 
separate from Eurasia. However, Africa is also divided into two biogeographical regions, created by the proximity of the north to the Mediterranean, and the presence of the Sahara as a major barrier. The result is two distinct zoogeographic zones - Saharo-Arabian and Afrotropical (more colloquially known as northern Africa and sub-Saharan Africa [39] (Figure 3).

In practice, discussion of the role of Africa in hominin evolution actually refers to subSaharan Africa, or more formally the Afrotropical Zoogeographic Zone (approximately the same as Wallace's Ethiopian Region) [39], for, with the exception of the fossils from Chad [22] (which are effectively on the boundary of the Afrotropical Zone), and, for more recent times, the North African coastal region, all hominin fossils of any significance come from sub-Saharan Africa.

Two points arise from the dual nature of Africa [47]. The first is that the Sahara is a major barrier, creating isolation of the sub-Saharan element. The Sahara was formed in the late Miocene, and was a progressively major barrier to movement and range expansion from the south (or indeed the north). Strictly speaking, in talking about African origins during the course of hominin evolution, it should be more clearly specified as the sub-Saharan Africa or the Afrotropical Zone. The second point is that although it is a major barrier, this has not been a constant. Based on the last glacial cycle, it is clear that in the cold phases Africa becomes arid, and the desertification intensifies and expands; conversely, at the beginning of periods of deglaciation, the region become much more humid, and as a result the Sahara contracts and is replaced by savannas - basically an expansion of the Afrotropical fauna [48]. At this point, there is much greater connectivity between sub-Saharan Africa and Eurasia, and it is then that range expansion northward occur. What seems clear across many faunas is that this is the directionality - from south to north, with few taxa making the journey in the opposite direction [47].

The 'two Africas' model is therefore a dynamic model, with periods of both isolation and connectivity. That connectivity is still through particular corridors - the Nile and the montane regions of the Central Sahara, most importantly creating the conditions for both isolation and range expansion and dispersals towards Eurasia [20,47]. The pulses - multiple dispersals - out of Africa are likely to have been regulated by the opening and closing of this barrier.

\section{Greater and lesser Africa}

The variable nature of Africa biogeographically - sometimes two distinct zoogeographic zones, sometimes one continuum - can be extended further. When the Sahara is a barrier, then in effect Africa - as in the Afrotropical Zoogeographic Zone - is reduced. During warm wet phases, it is greatly enlarged, and extends beyond the actual boundaries of the continent. If the Afrotropical faunas spread into the Saharo-Arabian regions, then these distributions will also extend further still. Dennell and Roebroecks have referred to "savannastan"[I6], as the total range of continuous habitat, stretching from East Africa as far as the north west frontier of India, and possibly beyond. While the distinctive zoogeographic zones suggest that there was never a complete swamping of the Palearctic by African fauna, nonetheless it is important to recognise that evolution operates on ecological boundaries, not geo-political and geological units. At various times - principally in the warmer marine isotope stages - 'evolutionary Africa' was larger than the continent, and at other times during cold phases - it was smaller (Figure 4). 


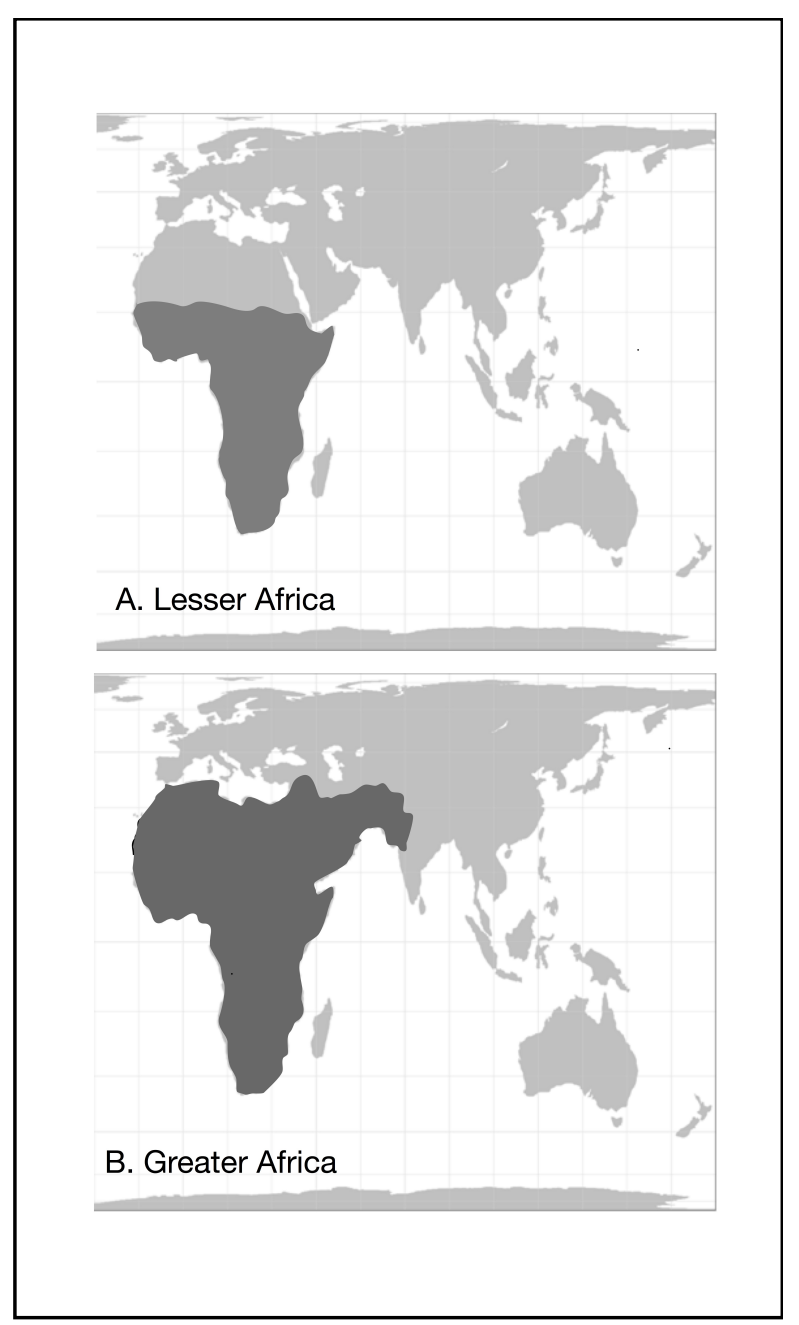

Figure 4. "Lesser" and "Greater" Africa: during the Pleistocene biogeographic distributions varied extensively in relation to climatic conditions; during more arid hases the Sahara was a barrier, and Eurasian and North African/Saharan Zones extended into Africa (A); during more humid phases the Sahara was less of a barrier and the Afrotropical Zone extended into Southern

greatest potential for dispersal. It should be added that both these basins are, relatively speaking, recent; the Turkana was an open fluvial system until the Lower Pleistocene [53], and the Nile has varied in size and catchment over time,
Another geographical perspective on Africa is to view it as a series of basins, each of which may form a distinct biogeographic zone. Although the formation of the EARS in the last five million years has altered some of these basins, and the Nile is both recent and unstable as a basin, they represent, in relation to hominin evolution, a long-term feature of the African landscape, with strong evolutionary consequences [49]. These basins have their own distinct responses to climatic change (as they largely relate to precipitation and run-off), and as a result, high levels of endemism in some cases. If hominins are both responding to environmental changes as other taxa, and subject to distance effects, then there may well have been asynchrony between basins, refugia networks occurring between adjacent basins, and particular patterns of dispersals between adjacent basins [50-52]. In this regard, two basins stand out as particularly interesting - Turkana and the Nile. These two have boundaries with four other basins, more than is the case for any other basin. They may therefore both act as refugia, and also have the

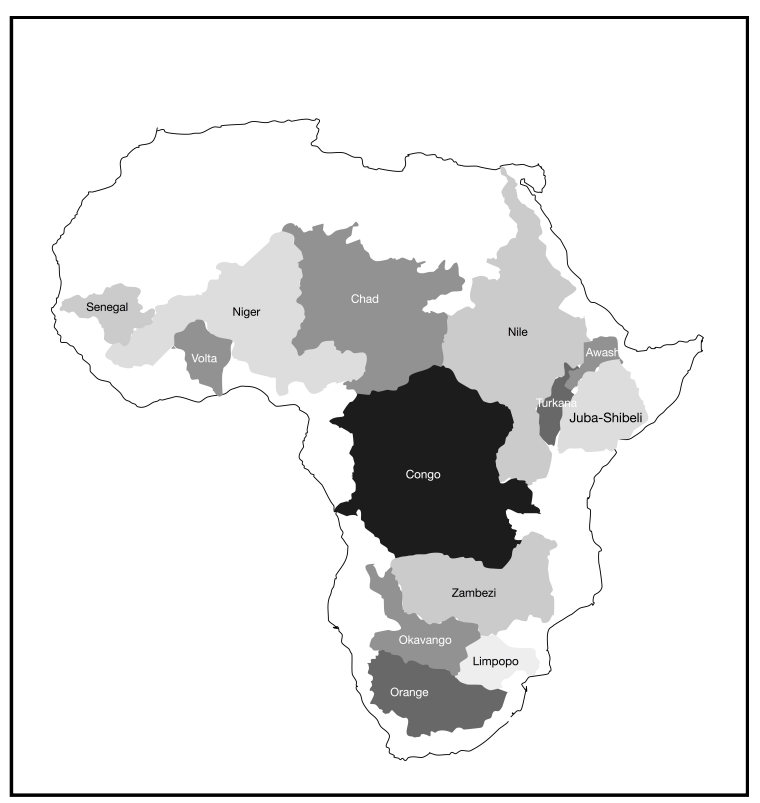

Figure 5. Africa is comprised of a number of large basins that act as biogeographical units (see text for discussion). Adapted from [51]. 
at various periods being much more reduced. It is also the only major basin that connects beyond Africa. (Figure 5).

\section{Biogeographic relationships across Africa}

Although we have characterised Africa as having two major zoogeographic regions, within those there is a considerable amount of diversity, part of which maps on to the basin structure. In a wide-ranging analysis across multiple taxa of animals and plants, Linder et al. [54] have used a bottom-up approach to determine what are these regions, and how they relate to each other. They identify eight major regions - Saharan, Sudanian, Somalian, Zambezian, Congolian, Guinean,

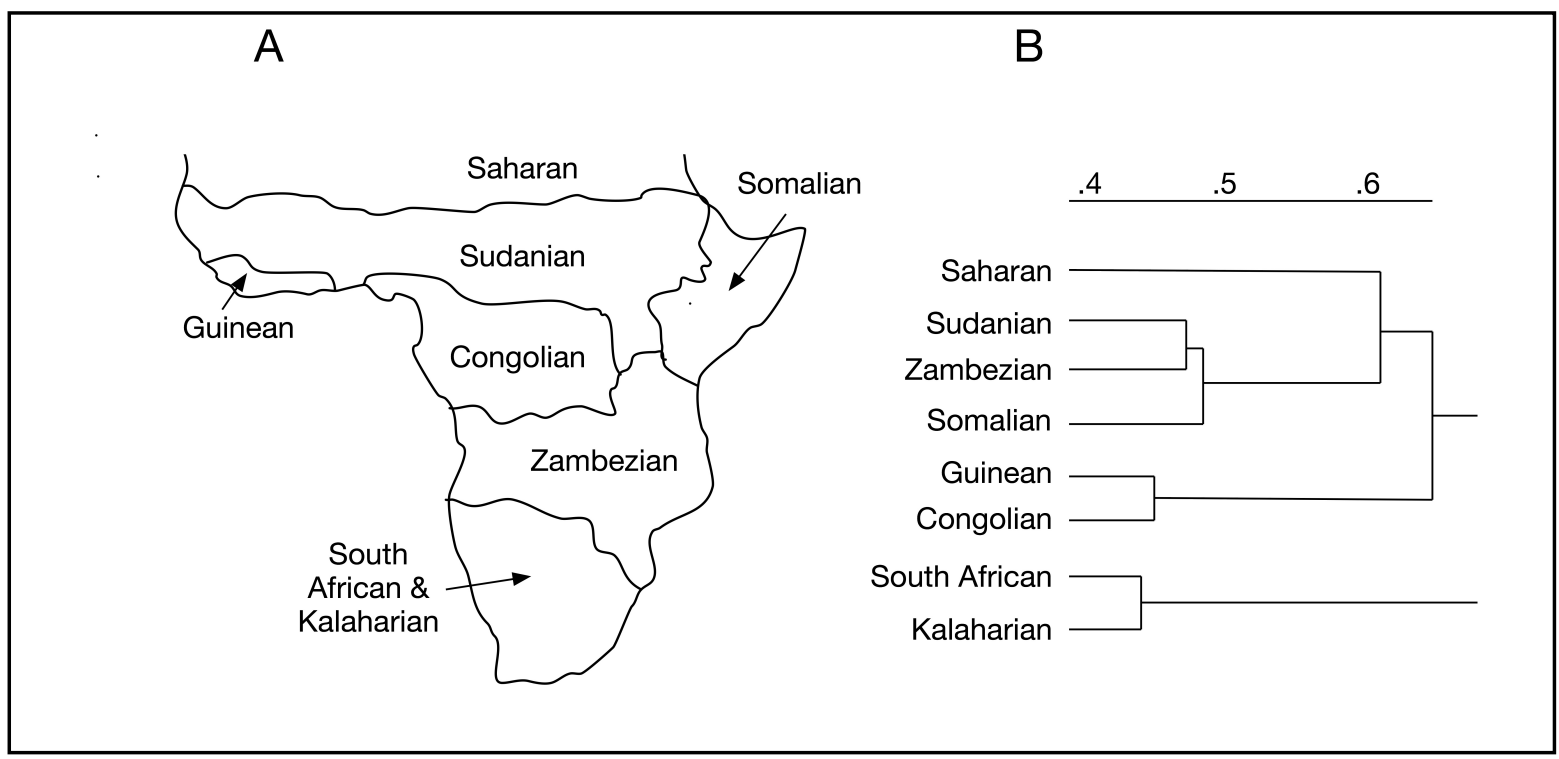

Figure 6. Map showing statistically defined biogeographical regions of Africa (A), and the degree of similarity between these (B). Adapted from [54].

Kalaharian and South African (Figure 6). Their analysis shows the 'relatedness' of the regions, which in effect indicates the degree of contact through dispersals or the presences of closely related species. In the analysis of mammals, the two forested regions of Central and West Africa are the most similar. The savanna regions are also similar, but divide quite strongly into northern (Sudanian) and southern (Zambezian) zones, suggesting a natural break in evolutionary patterns. The Saharan and Somalian zones link next to the savannas, and it is the southern African zones (Kalaharian and South African) that are the most disparate. The 'savanna' regions are the most similar to each other (Figure 6). Other groups of plants and animals show slightly different patterns. These analyses would suggest that eastern Africa is, in terms of mammalian evolution and ecology, more loosely linked to northern rather than southern Africa, and, as discussed above, the Sahara is a variable barrier. An interesting question is the nature of the barriers between equatorial and southern Africa, whether these are the result of biotic competition or some more physical or climatic effect.

\section{East-West versus North-South}

The analysis of biogeographical zonation of Africa is based on current distributions, but, as discussed above, this is not stable. At certain times Africa is more arid, and the more open environments expand at the expense of the more humid ones. When this happens, the "corridors" of 


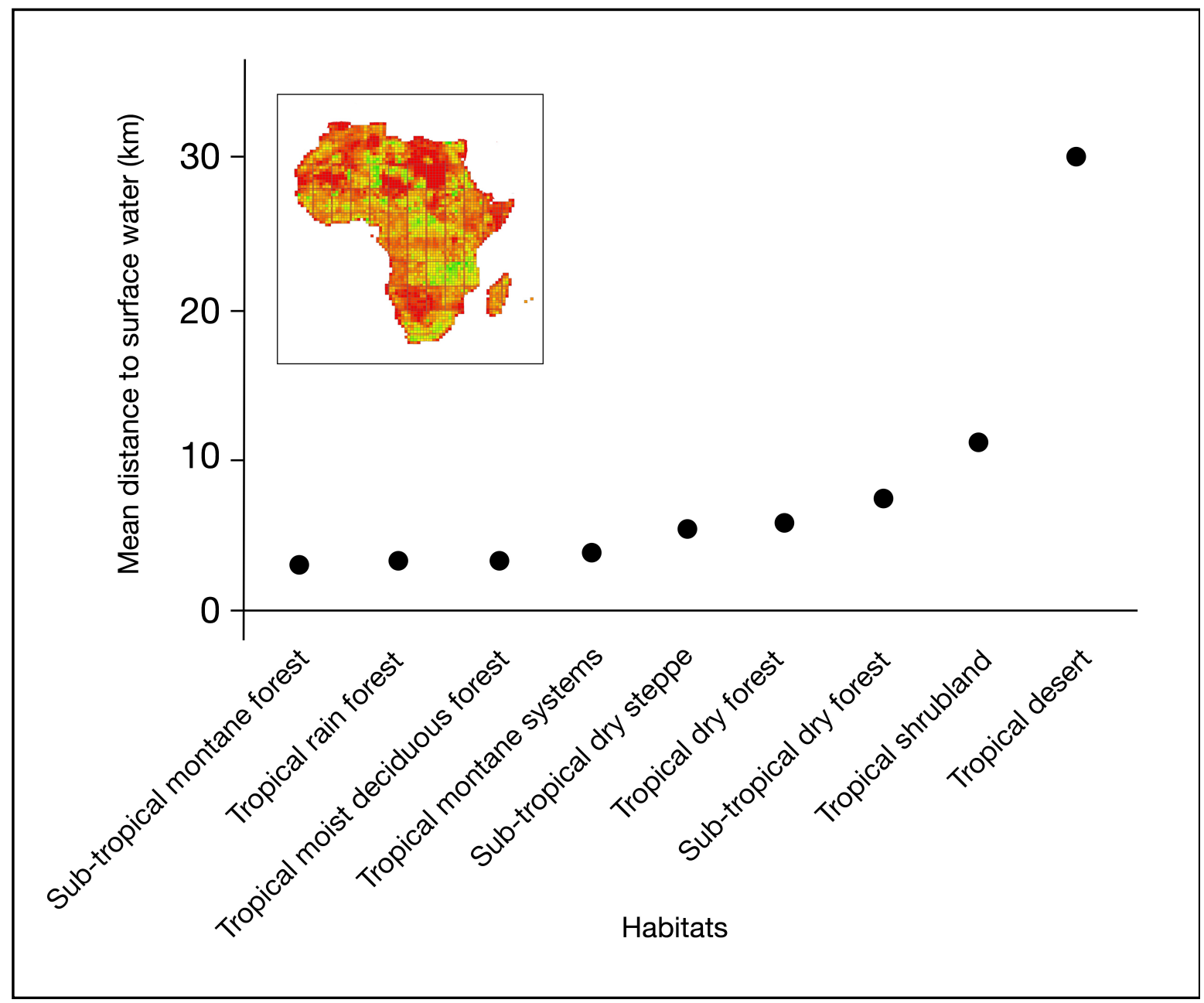

Figure 7. Mean distance to the nearest surface water for different habitats in Africa. Inset map shows the density of surface water locations across Africa (red represents lowest, green

sub-Saharan Africa" are north-west, cutting the equatorial rainforests into eastern and western parts [46]. However, at that time the Sahara is expanded, acting as a barrier to further northern expansion. When the climate is more humid, in contrast, the tropical forests expand, and cut the savanna regions into northern (Sudanian) and southern (Zambezian), creating a continuous forested distribution from coast to coast. At these times, however, the Sahara would have been an extension of the Sudanian region, and therefore a conduit to the north and Eurasia. This oscillation would mean that Africa alternates between a region with a north-south axis of movement, with a northern cap, and periods when it has an east-west-axis, but reduced barriers to the north [2I].

\section{Mosaic environments}

Another perspective on Africa is as a set of mosaic environments. Where Eurasia is dominated by latitudinally-banded habitats, Africa is a more patchy set of environments, shaped by not just latitude, but also topography, relief, and rainfall patterns. The result, particularly on the eastern side of the continent, is a mosaic structure of habitats. Mosaic environments are effectively regions with high environmental diversity, where it is possible to travel relatively short distances and cross a number of habitat boundaries. It has been argued that these mosaic habitats can promote local adaptations, form refugia and high levels of endemism, and will consequently have high rates of 
speciation. These mosaic habitats often coincide with biodiversity hotspots and also areas with high extinction risk. Palaeoanthropologists have often proposed that mosaic environments played a critical role in the early stages of hominin evolution [55, 56], and the EARS is particularly noted for the high level of habitat diversity occurring within it. And in particular greater seasonality, a key selective pressure [57].

\section{Topography}

One of the variables that promotes a high level of mosaicism in a region is a variable topography, or high relief. King and colleagues have made a strong case for linkage between high relief and hominin evolution in Africa [57-59]. The argument is that traits such as bipedalism are advantageous in regions with high relief, as well as providing suitable habitats in terms of resource availability and distribution. They also suggest that the distribution of hominin occupation, and the regions to which they disperse tend to be ones with high topographic relief. As always, there may be taphonomic factors involved, but there are also good ecological reasons for such a correlation, including the presence of water, shelter and protection, and good hunting conditions.

\section{Water}

While the requirements and availability for food resources will vary with habitat, water is a constant. Hominins are a strongly water dependent animal [55], and there are arguments that their dependence upon sweating for thermoregulation makes them particularly water-dependent. Access to surface water is critical, and this in turn varies enormously. In deserts the mean distance between water sources is over $30 \mathrm{~km}$; for most other habitats it is between 3 and $5 \mathrm{~km}$, and in the savanna/bush environments in which it is hypothesised much of human evolution occurs, it is between 5 and Io $\mathrm{km}$ [60] (Figure 7). These average figures, of course, conceal considerable variation, and it is likely that actual landscape distributions of hominins will have been patchily determined by water distribution.

\section{Ecological and biogeographic context for hominin evolution in Africa}

The abundant genetic, archaeological and palaeontological evidence that places the Afrotropical realm at the centre of many aspects of hominin evolution implies that there are many reasons for focusing on the ecological and biogeographic context of Africa to understand why this is the case. Several factors contribute to that context, and these emphasise not the homogeneity of Africa relative to the rest of the world, but the variable and dynamic nature of it. That variability can explain not just the importance of the Afrotropical realm, but why particular parts of it may play key roles in hominin evolution. Among these are:

I. Areas of high diversity, which occur both in the rain forests and in the EARS may act as sources for evolutionary novelty, with higher rates of speciation and therefore the potential for dispersals of new populations to of their zones of endemism. These areas of high diversity may relate to broader climatic, topographic variables, habitat distribution and diversity and water availability.

2. From the perspective of evolutionary geography, Africa is neither homogenous nor stable. As an evolving community of plants and animals, geographical facts have shaped the patterns observed, and in turn these patterns show a strong spatial structure. Large scale basin 
structures play a strong role, although there are also broader zoogeographic structures. Changes in these over time result in different configurations of Africa and the Afrotropical realm - 'greater' and lesser, with or without a Saharan barrier, and with either a north-south continuity of open savannas, or an east-west continuity of forests. These shifts are important in terms of isolation and patterns of gene flow.

3. Actual geographical position is also an important factor. The similarity coefficients of mammalian regions [54] showed, for example that southern Africa was relatively isolated from the rest, while Holt et al. [39] also showed how the Sahara was more closely related to the south-western parts of Asia. The implication is that these are distance effects, and are likely to have shaped hominin population relationships and probabilities of dispersal. Put simply, it is impossible to disperse into Eurasia without going through north-eastern Africa.

\section{African evolutionary geography and hominin evolution}

Hominin evolution is a complex and multiphase process that occurs over more than seven million years on current evidence. As stated at the outset, much of that occurs in the Afrotropical realm. How much can the evolutionary geography and ecology of Africa described above provide insights into these events. Table 2 shows the principal elements of African evolutionary geography discussed, and the implications for patterns of hominin evolution.

Table 2. Evolutionary processes and patterns discussed in the text, and applications to hominin evolution

Evolutionary geography component

Latitudinal gradient: higher taxic diversity in equatorial Africa relative to both northern and southern Africa, and Eurasia

Sahara as a variable barrier: under warmer and wetter conditions, the Sahara is an extension of Sudanian Zone, and does not act as a barrieropen

Sahara as a variable barrier: under drier and colder conditions the Sahara expands and forms a barrier between northern and southern Africa.

\section{Hominin applications and hypotheses}

- More hominin species have African origins

- More hominin species occur only in Africa

- There is higher hominin diversity in tropical Africa compared to northern and southern

- Continuity of hominin populations across Africa and into southern Eurasia during wet phases;

- Out of Africa dispersals during wet phases;

- Admixture and cultural contact between northern African and southern Eurasian populations during wet phases

- Isolation of sub-Saharan hominin populations;

- Early hominins limited to sub-Saharan Africa

- Divergence of Eurasian and sub-Saharan lineages, such as Neanderthal/Denisovans and ancestors of AMH. 
Greater Africa: the more open environment elements of Africa to the east and north expand into Eurasia ("Savannastan")

Lesser Africa: environmental differences and barriers such as the Sahara lead to a more restricted Afrotropical geographical range

Inter-continental endemism: tropical areas such as Africa have higher levels of endemism relative to Eurasia

Intra-Africa endemism: East Africa has higher levels of endemism than other parts of Africa

- Northern Africa and southern Eurasia could have formed a hominin metapopulation during these times.

- This may fit the observed complex diversity of early Homo between 2 and I.6 Ma.

- Some genetic evidence may indicate a similar metapopualtion after the early dispersals of modern humans, but prior to the separation of Eurasians and Papuans/ Australians

- Restricted and fragmented populations in sub-Saharan Africa may have created the conditions for population structuring implied by the human evolutionary genetics

- The Africa v Eurasia phylogeny proposed for Lower and Middle Pleistocene Homo may reflect the sustained nature of 'lesser Africa' at various periods.

- Most hominin taxa originate in Africa;

- Most hominin taxa occur in Africa

- Relative to other parts of Africa, East Africa has higher rates of origin of taxa and higher diversity

- If hominin lineages evolved primarily in eastern Africa, then there would be a greater correlation between coevolutionary and dispersal events in that region compared of other parts of Africa.

Co-evolution: due to competitive interactions and shared environmental dynamics, there will be co-evolution among lineages in the same regions

\section{African basins and biogeographic} phylogeny: biogeographical zonation in Africa is structured to a large extent by major topographic basins, which determine levels of endemism and zoogeographic relationships between basins

\section{East-West humid connectivity versus} north-south savanna connectivity: during arid phases the primary routes for range dispersals are north south, by open habitat organisms; during humid phases it is east-west and dominated by forest organisms
- If hominin lineages evolved primarily in eastern Africa, then there would be a greater correlation between coevolutionary and dispersal events in that region compared of other parts of Africa.

- Patterns of hominin physiology, affinity and dispersals should match the distribution of African basins, and their proximity to each other

- The relative isolation of the southern African biomes; the split between Zambian and Sudanian savannas

- Southern Africa should have a hominin evolutionary history that reflects greater levels of isolation and terminal refugia, possibly with later extinction dates

- If hominins were largely adapted to the more open environments of sub-Saharan Africa, then during more arid phases there would have been range expansion and dispersals from eastern to southern Africa (and vice-versa); during warmer and wetter phases, eastern and southern Africa would have been less connected.

- Little is known about the western extensions of hominins, but these would have been more likely during more arid phases

- Although taphonomy may well be a factor, the high level of hominin diversity in East Africa coincides with the high levels of habitat diversity found in the EARS
Mosaic environments: some African
regions have high environmental diversity, which promotes local adaptations, form refugia and high levels of endemism 
Topographic variation: variation in relief promotes habitat diversity and isolation, and thus species diversity and endemism

Water: water is one of the primary determinants of distribution and habitat, and in addition to its broader impact on productivity, surface water availability constrains water-dependent species.
- Hominins may have had a preference for areas with relatively high relief, although this would be difficult to disentangle from taphonomic factors.

- At the meso- and microscale, hominin distributions (and their archaeological record) will be restricted to areas with surface water.

Many of the underlying ecological principles and hominin implications relate primarily to distributions and diversity - broadly speaking macroevolutionary patterns that are shaped by geographical factors. This is, in essence, the contribution of evolutionary geography. Most of the expectations for hominin evolution are that there should be greater diversity, endemism and evolutionary novelty in Africa compared to other regions, and in tropical Africa relative to other parts of Africa. The expectations from evolutionary geography can apply to all phases - the diversity of the earliest hominins with several genera, probably associated with the emerging adaptations to grounddwelling through bipedalism, the peak diversity of Plio-Pleistocene hominins, the complex biogeography of early Homo across eastern Africa and into the Caucasus, and the multiple dispersals of novel taxa from Africa into Eurasia during the Pleistocene. They are all broadly consistent with the current data, although, as stressed at the outset, it is not possible to entirely disentangle these from taphonomic factors.

What is less clear is the extent to which the adaptive trends of hominin evolution - as opposed to macroevolutionary patterns - are also influenced strongly by the African context. In general terms they must be, as the adaptive traits of hominins are solutions to the problems of survival and reproduction at particular times and in particular places in Africa. For this a different approach is required, one that is based more closely on the adaptive traits of hominins - bipedalism, technology, changes in life history strategy, changes in diet, encephalisation and the development of an enhanced capacity for culture. - in other words whether this approach relates only to macroevolutionary patterns, or microevolution and adaptation. For example, what are the particular elements of the African evolutionary and ecological environment that makes bipedalism an optimal solution for a hominoid? Or, what adaptive problems does the development of lithic technology solve for hominins in East Africa around or before 3.3 Ma? To put it another way, while the evolutionary geography might predict a higher rate of speciation and evolutionary novelty in Africa compared to other regions, further components and a much more fine-grained analysis would need to be added to the model to explain why that novelty might be bipedalism or larger brains.

\section{Conclusions}

Conclusive evidence from genetics, archaeology and palaeontology has shown the central role of Africa in hominin evolution. That centrality can be measured by the number of significant first appearances, by the high levels of evolutionary endemism, by the high level of taxonomic diversity, and the strong directionality of dispersals from Africa to Eurasia across the Pleistocene. Evolutionary genetics is also showing that Africa was the source for the ancestral modern human populations, and that genetic diversity declines from Africa. These are straightforward facts, and appear to be as secure 
as any major finding in evolutionary history. Although there is inevitably a form of phylogenetic bias involved - given the original African origin of the hominin clade and its solely African distribution for several million years, that this pattern continues after the first Eurasian dispersals remains an interesting observation.

These facts sum together as the Afrotropical Model of hominin evolution, namely that hominin evolution is rooted in a distinct zoological region. The challenge addressed in this paper has been to connect this model to a broader range of evolutionary theory and biology. Evolutionary geography provides one such body of theory; using the way in which evolutionary processes play out over different spatial scales provides the basis for exploring whether what is seen for hominin evolution reflects the broader rules of biogeography - the higher levels of endemism and speciation in the tropics, the operation of latitudinal gradients rules, and comparisons with evolutionary patterns in other groups of plants and animals. All of these lead to the conclusion that there are good reasons why it might be expected that such phenomena as higher hominin diversity occurs in Africa compared to other continents, or why dispersals tend to be from Africa to Eurasia. This approach, while largely confirming current findings, could be extended to develop more detailed predictions for hominin evolution. What might be the next challenge would be consider the cases in hominin evolution that do not conform to these general rules - the possibility of dispersals from Eurasia into Africa at the base of the African ape/human lineage, the possibility of convergence in behaviour between Eurasian and African hominins, the Eurasian divergence of Neanderthal and Denisovan lineages - in other words, developing an evolutionary geography framework for Eurasia.

Finally, it is worth emphasising what is not claimed in this paper - that hominin evolution could only have occurred in Africa. The broad rules of evolution that have been used to understand why there is a consistency between principles and observations within hominin evolution are not fixed and deterministic rules, but statistical properties, patterns and trends that are more likely to occur than not. But evolution is also full of exceptions, of unusual conditions, of chance and convergence. If - to develop Gould's thought experiment [6I] - we were to rerun the tape of life a million times, in most of those evolutionary histories 'hominin' evolution probably would not occur. Among those where it did, there would, no doubt, be histories where the emergence of a highly intelligent and cultural creature occurred under different geographical conditions, in Asia, in Europe, in the Americas. But, the largest proportion of alternative histories are likely to be in the tropics and in Africa.

\section{Acknowledgements}

This paper is part of Marta Mirazón Lahr's European Research Council Advanced Award (IN-AFRICA, ERC 295907), and also received support from the Leverhulme Trust. I thank the Société d'Anthropologie de Paris for the invitation to address this topic at their annual meeting in 20I7, and Marta Mirazón Lahr for input of ideas and discussion. 


\section{References}

I. Dart RA (1925) Australopithecus africanus: The Man-Ape of South Africa. Nature II5(2884):I95I99.

2. Reader J (20II) Missing Links (OUP Oxford) Available at: http://books.google.co.uk/books? $\mathrm{id}=\mathrm{N} 24 \mathrm{IFaDfUcQC} \&$ printsec $=$ frontcover\&dq=reader+missing + links\&hl=\&cd=I\&source=gbs api.

3. Boyle E, Wood B (2017) Human Evolutionary History. Evolution of Nervous Systems Volume 4 The Evolution of the Human Brain: Apes and Other Ancestors, ed Kaas J (Academic Press, New York), pp 19-36. 2nd Ed.

4. Wood B, K. Boyle E (2016) Hominin taxic diversity: Fact or fantasy? Yearb Phys Anthropol Phys Anthropol 159:S37-S78.

5. Prado-Martinez J, et al. (2013) Great ape genetic diversity and population history. Nature 499(7459):47I-5.

6. Darwin C (I871) Descent of Man and Selection in Relation to Sex (Murray, London).

7. Cann RL, Stoneking M, Wilson AC (1987) Mitochondrial DNA and human evolution. Nature 325:3I-35.

8. Botigué LR, et al. Gene flow from North Africa contributes to differential human genetic diversity in southern Europe. pnas.org. Available at: http://www.pnas.org/content/ IIO/29/II79I.abstract.html?etoc.

9. Seguin-Orlando A, et al. (2014) Genomic structure in Europeans dating back at least 36,200 years. Science 346(6213):III3-III8.

Io. Fu Q, et al. (2014) Genome sequence of a 45,000-year-old modern human from western Siberia. Nature 5I4(7523):445-9.

II. Wang CC, Farina SE, Li H (2013) Neanderthal DNA and modern human origins. Quat Int 295:I26-I29.

I2. Fleagle JG, Shea JJ, Grine FE, Baden AL, Leakey RE (20I0) Out of Africa I (Springer) Available

I3. Stringer CB, Andrews $\mathrm{P}$ (1988) Genetic and fossil evidence for the origin of modern humans. Science 239:1263-I268.

I4. Mirazon Lahr M, Foley RA (1994) Multiple dispersals and modern human origins. Evol Anthropol Issues, News, Rev 3(2):48-60.

I5. Fuss J, et al. (20I7) Potential hominin affinities of Graecopithecus from the Late Miocene of Europe. PLoS One 12(5):eoI77127.

I6. Dennell R, Roebroeks W (2005) An Asian perspective on early human dispersal from Africa. Nature 438(707I):I099-IIO4.

I7. Richter D, et al. (2017) The age of the hominin fossils from Jebel Irhoud, Morocco, and the origins of the Middle Stone Age. Nature 546(7657):293-296.

I8. Hublin J-J, et al. (20I7) New fossils from Jebel Irhoud, Morocco and the pan-African origin of Homo sapiens. Nature 546(7657):289-292.

I9. Hillebrand H (2004) On the Generality of the Latitudinal Diversity Gradient. Am Nat I63(2): I92-2II.

20. Mirazon Lahr M, Foley RA (1998) Towards a theory of modern human origins: geography, demography, and diversity in recent human evolution. Am J Phys Anthropol Suppl 27:I37-176.

2I. Foley RA (1999) Evolutionary geography of pliocene African hominids. eds Bromage TG, Schrenk F (Oxford University Press), pp I-26.

22. Brunet $\mathrm{M}$, et al. (2002) A new hominid from the upper Miocene of Chad, central Africa. Nature 4I8(6894):I45-I5I.

23. Maslin MA, et al. (20I4) East African climate pulses and early human evolution. Quat Sci Rev IOI:I-I7. 
24. Brain CK (198I) The Hunters or the Hunted: an Introduction to African Cave Taphonomy (University of Chicago Press, Chicago).

25. Deacon HJ, Shuurman R (1992) The origins of modern people: The evidence from Klasies River. eds Brauer G, Smith FH (Balkema, Rotterdam), pp I2I-I29.

26. d'Errico F, Henshilwood C, Nilssen P (200I) An engraved bone fragment from c. 70,000-yearold Middle Stone Age levels at Blombos Cave, South Africa : implications for the origin of symbolism and language. Antiquity 75(288):309-318.

27. McDougall I, Brown FH, Fleagle JG (2005) Stratigraphic placement and age of modern humans from Kibish, Ethiopia. Nature 433(7027):733-736.

28. White TDT, et al. (2003) Pleistocene Homo sapiens from Middle Awash, Ethiopia. Nature 423(694I):742-747.

29. $\mathrm{Fu} \mathrm{Q}$, et al. (2013) A revised timescale for human evolution based on ancient mitochondrial genomes. Curr Biol 23(7):553-9.

30. Stringer C (2016) The origin and evolution of Homo sapiens. Philos Trans R Soc B Biol Sci 37I(I698):20150237.

3I. Higham $\mathrm{T}$, et al. (20I4) The timing and spatiotemporal patterning of Neanderthal disappearance. Nature 5I2(75I4):306-309.

32. Hershkovitz I, et al. (20I5) Levantine cranium from Manot Cave (Israel) foreshadows the first European modern humans. Nature:I-I3.

33. Nigst PR, et al. (20I4) Early modern human settlement of Europe north of the Alps occurred 43,500 years ago in a cold steppe-type environment. PNAS III(40):I4394-I4399.

34. Rolland J, Condamine FL, Jiguet F, Morlon H (20I4) Faster Speciation and Reduced Extinction in the Tropics Contribute to the Mammalian Latitudinal Diversity Gradient. PLoS Biol I2(I). doi:I0.I37I/journal.pbio.IOOI775.

35. Nettle D (1998) Explaining global patterns of language diversity. J Anthropol Archaeol I7(4):354374 .

36. Collard I, Foley RA (2002) Latitudinal patterns and environmental determinants of recent human cultural diversity: do humans follow biogeographical rules? Evol Ecol Res 4(3):37I-383.

37. Amano T, et al. (20I4) Global distribution and drivers of language extinction risk. Proc Biol Sci 28I(I793):20I4I574-

38. Foley RA (2004) The evolutionary ecology of linguistic diversity in human populations (na).

39. Holt BG, et al. (2013) An Update of Wallace's Zoogeographic Regions of the World doi:Io.II26/science. I23754I.

40. Kier G, et al. (2009) A global assessment of endemism and species richness across island and mainland regions. Proc Natl Acad Sci U S A I06(23):9322-7.

4I. Fortelius $\mathrm{M}$ (2016) An ecometric analysis of the fossil mammal record of the Turkana Basin. Philos Trans R Soc London Ser B 371:20150232.

42. Janis CM, Wilhelm PB (1993) Were there mammalian pursuit predators in the tertiary? Dances with wolf avatars. J Mamm Evol I(2):I03-I25.

43. Foley RA (1984) Early man and the Red Queen: tropical African community evolution and ecology. ed Foley RA (Academic Press, New York and London), p 85-IIO.

44. Se galen L, Lee-Thorp JA, Cerling T (2007) Timing of C4 grass expansion across sub-Saharan Africa. J Hum Evol 53(5):549-559.

45. Blumenthal SA, et al. (20I7) Aridity and hominin environments. Proc Natl Acad Sci (I):20I700597.

46. Foley RA (1999) The evolutionary geography of Pliocene hominids. African Biogeography, Climate Change and Human Evolution, eds Bromage TG, Schrenk F (Oxford University Press, Oxford), pp 328-348. 
47. Mirazon Lahr M (20I0) Saharan corridors and their role in the evolutionary geography of "Out of Africa I." Out of Africa I, eds Fleagle J, Baden A, Grine F, Shea J, Leakey R (Springer), pp 2746.

48. Armitage SJ, et al. (2007) Multiple phases of North African humidity recorded in lacustrine sediments from the Fazzan Basin, Libyan Sahara. Quat Geochronol 2(I-4):I8I-I86.

49. Kingdon J (1989) Island Africa (Academic Press, London).

50. Foley RA (2013) Comparative Evolutionary Models and the "Australopith Radiations." eds Reed KE, Fleagle JG, Leakey RE (Springer), pp I63-I74.

5I. Foley RA, Maíllo-Fernández JM, Mirazon Lahr M (2013) The Middle Stone Age of the Central Sahara: Biogeographical opportunities and Technological strategies in later human evolution. Quat Int 300:153-I70.

52. Mirazón Lahr M, Foley RA (2016) Human evolution in Late Quaternary Eastern Africa. Africa from MIS 6-2: Population Dynamics and Paleoenvironments, eds Jones SC, Stewart BA (Springer, Dordrecht), pp 2I5-23I.

53. Feibel CS (2OII) A Geological History of the Turkana Basin. Evol Anthropol Issues, News, Rev 20(6):206-2I6.

54. Linder HP, et al. (2OI2) The partitioning of Africa: statistically defined biogeographical regions in sub-Saharan Africa.J Biogeogr 39(7):II89-I205.

55. Foley RA (1987) Another Unique Species: patterns in human evolutionary ecology (Longman, Harlow).

56. Reynolds SC, Wilkinson DM, Marston CG, O'Regan HJ (2015) The mosaic habitat concept in human evolution: past and present. Trans $R$ Soc South Africa 326:57-69.

57. Foley RA (1993) The influence of seasonality on hominid evolution. eds Ulijaszek SJ, Strickland S (Cambridge University Press), pp I7-37.

58. Winder IC, et al. (20I5) Evolution and dispersal of the genus Homo: A landscape approach. J Hum Evol 87:48-65.

59. Kübler S, et al. (2016) Edaphic and Topographic Constraints on Exploitation of the Central Kenya Rift by Large Mammals and Early Hominins. Open Quat 2(o). doi:I0.5334/oq.2I.

6o. King G, Bailey G (2006) Tectonics and human evolution. Antiquity 80(308):265-286.

6I. Lennard J (20II) Surface water distribution in Africa and its impact on human evolution: a GIS approach. Dissertation (University of Cambridge).

62. Gould SJ (1996) Wonderful Life: The Burgess Shale and the Nature of History (W W Norton, New York).

63. McBrearty S, Brooks AS (2000) The revolution that wasn't: a new interpretation of the origin of modern human behavior. J Hum Evol 39(5):453-563.

64. Day MH, Stringer CB (I99I) The Omo Kibish Cranial Remains and Classification within the Genus Homo. Anthropologie 95(2-3):573-594.

65. Tryon CA, McBrearty S (2002) The Middle Stone Age of the southern Kapthurin Formation, Baringo, Kenya.J Hum Evol 42(3):A37-A37.

66. Asfaw B (1983) A new hominid parietal from Bodo, Middle Awash Valley, Ethiopia. Am J Phys Anthropol 6I:367-37I.

67. Lepre CJ, et al. (20II) An earlier origin for the Acheulian. Nature 477(7362):82-85.

68. Brown F, Harris J, Leakey R, Walker A (1985) Early Homo-Erectus Skeleton from West Lake Turkana, Kenya. Nature 3I6(603I):788-792.

69. Semaw S, et al. (1997) 2.5-million-year-old stone tools from Gona, Ethiopia. Nature 385(66I4): 333-336.

70. Villmoare B, et al. (2015) Early Homo at 2.8 Ma from Ledi-Geraru, Afar, Ethiopia. Science 347(6228):1352-I355. 
In Press: Bulletins et Mémoires de la Société d'Anthropologie de Paris (BMSAP)

71. Harmand S, et al. (20I5) 3.3-million-year-old stone tools from Lomekwi 3, West Turkana, Kenya. Nature 52I(7552):310-315.

72. Leakey MG, Feibel CS, McDougall I, Ward C, Walker A (1998) New specimens and confirmation of an early age for Australopithecus anamensis. Nature 393(6680):62-66. 